\title{
A INTERVENÇÃO DA GEOMORFOLOGIA NA VIABILIZAÇÃO AMBIENTAL DE UNIDADES HIDRELÉTRICAS-UHE'S: EXPERIÊNCIAS DE MINAS GERAIS
}

\author{
Allaoua Saadi $(*)$
}

\section{UNIDADESHIDRELÉTRICAS,LICENCIAMENTO AMBIENTALEGEOMORFOLOGIA}

No Brasil, grande parte da energia elétrica é produzida nas chamadas Unidades Hidrelétricas-UHE's compostas, basicamente, por barragem e lago gerado pelo represamento de um rio. Represamentos são também implantados para comporem sistemas de abastecimento urbano, ou ainda visando perenização e/ou regularização de vazões.

O Estado de Minas Gerais, junto com áreas marginais pertencentes aos estados vizinhos, caracteriza-se como a caixa d'água do país, devido ao fato de a maior parte das grandes bacias hidrográficas brasileiras, extraamazônicas, terem suas nascentes localizadas num de seus planaltos ou serras. Isso confere a essa região um importante papel na geração de energia hidrelétrica, de onde deriva a implantação de um grande número de barramentos de rios com as respectivas represas e usinas energéticas, compondo as denominadas Unidades Hidrelétricas-UHE's.

Os problemas ambientais decorrentes deste tipo de empreendimento são, ao mesmo tempo, extremamente variados e, geralmente, de significativa magnitude. Por isso a legislação ambiental exige a elaboração de estudos, que visam avaliar as implicações desses empreendimentos sobre o meio ambiente, considerado numa visão ampla, que inclui tanto as componentes biofísicas, quanto todos os elementos de caráter sócioeconômico.

Desde a promulgação da Resolução CONAMA 001/ 86 (de 23/01/1986), que veio regulamentar a Lei Federal n 6.938 (Lei Nacional do Meio Ambiente, de 31/08/1981), estabelecendo as normas para a Avaliação de Impactos Ambientais, a implantação das UHE's, bem como a de qualquer empreendimento de médio a grande porte, está condicionada a um processo de licenciamento ambiental atrelado à elaboração e respectiva aprovação de um Estudo de Impactos sobre o Meio Ambiente/Relatório de Impactos sobre o Meio Ambiente- EIA/RIMA. Em casos muito específicos, justificados pelo porte reduzido ou por imperativos estratégicos, o orgão de licenciamento ambiental pode reduzir a exigência à elaboração de um Relatório de Controle Ambiental-RCA e respectivo Plano de Controle Ambiental-PCA. A contribuição da geografia à resolução dos problemas da avaliação ambiental ligados a projetos deste tipo, tem sido de grande valia no que diz respeito ao trato das questões tanto de ordem sócio-econômica como bio-física.

Em particular a geomorfologia tem sido usada como ferramento de fundamental importância, para formatar respostas a questões que ultrapassam de longe os clássicos problemas de erosão, preocupação permanente dos geomorfólogos (12). Este trabalho tem por objetivo retratar este papel, à luz de experiências tiradas da execução de alguns trabalhos realizados para projetos de portes variados: Nova Ponte (rio Araguarí), Irapé (rio Jequitinhonha), Sapucaia (rio Paraíba do Sul), Igarapava (rio Grande) e rio Manso (rio Manso-bacia do rio Paraopeba), para os de médio e grande porte, Caraíbas (ribeirão Caraíbas-bacia do rio Salinas), Guilman-Amorim (rio Piracicaba) e Porto Estrela (rio Santo Antônio), para os de pequeno porte.

Com base nisso, pode se classificar as principais contribuições da geomorfologia à viabilização ambiental das UHE' em três (3) dimensões fundamentais, quais sejam: (a) papel de apoio direto a áreas técnicas correlatas, (b) suporte espacial e conceitual para as sínteses geo-ambientais e (c) critério (ou contribuição) de caráter decisional sobre problemas técnicooperacionais específicos.

\section{A GEOMORFOLOGIA COMO APOIODIRETOA ÁREAS TÉCNICAS CORRELATAS}

A organização e o comportamento geomorfológico de uma dada região são resultados da circulação de fluxos de energia e matéria, durante períodos de tempos variados e sob controle das condições e/ou dinâmicas geológicas, climáticas e hidrológicas. Paralelamente à construção do arcabouço geomorfológico, definem-se todas as outras características ambientais da biosfera, tais como solos, vegetação, fauna, entre outros, configurando, claramente, um sistema de ações e retroações já de domínio público. A consideração dessas interações em projetos executivos permite agilizar os estudos e diminuir seus custos, programando o escopo dos estudos geomorfológicos para auxiliar a realização dos estudos de geologia, pedologia e geotecnia, entre 
outros (5).

No primeiro caso, o auxílio que o conhecimento da geomorfologia regional pode oferecer aos estudos geológicos é relativamente óbvio, apesar dos efeitos do intenso intemperismo sob condições bioclimáticas intertropicais.

Em primeiro lugar, os mapas de compartimentação geomorfológica das áreas de influência das UHE's, ao usarem associações de feições de relevo interpretadas em termos genéticos, estarão representando, também, versões preliminares dos mapas geológicos, pois a experiência demonstra que os contornos dos compartimentos morfo-estruturais correspondem, quase exatamente aos de unidades geotectônicas, em regiões de escudos $(6,8)$. Em seguida, a interpretação da repartição espacial das feições de erosão e acumulação sedimentar, fornece indicações sobre as variações litológicas e as estruturas tectônicas que ocorrem dentro dos compartimentos e em suas margens $(6,8,10)$. Em alguns casos, variações morfológicas de detalhe, dentro de um mesmo compartimento morfo-estrutural, indicam diferenças de fundamental importância na geometria das estruturas tectônicas numa mesma unidade litológica: cristas quartzíticas arredondadas e agudas corresponderam, respectivamente, a klippes e rampas frontais de empurrões, no Planalto do Espinhaço Setentrional (8).

No caso da pedologia, a compartimentação geomorfológica, associada à caracterização das coberturas superficiais constitui um suporte espacial fundamental para a elaboração do esboço inicial do mapa pedológico (5). As relações entre morfogênese e pedogênese, enfocadas em suas dimensões paleogeográficas e geodinâmicas, permitem destacar associações como as encontradas nos casos seguintes, entre:

- resíduos de superfícies de aplainamento terciárias e latossolos, com variações desses relacionadas com a litologia $(6,8,10)$;

- encostas convexas com mantos saprolíticos/ coluviais e associações de solos podzólicos e latossólicos $(2,10)$;

- encostas convexas ou retilíneas em áreas erodidas e predominância de cambissolos $(6,8,10)$;

- planícies aluviais úmidas e solos hidromórficos, com variações desses função dos micro-ambientes fluviais (2);

- baixos terraços aluviais em regiões semi-áridas e solos brunos não cálcicos ou solos salinos (solonetz e/ou solontchaks), variações essas função da proximidade da área fonte de sais e, também, do grau confinamento do fundo de vale (6);

Por outro lado, a avaliação do valor de uso dos solos para fins, seja de indenização pelas terras desapropriadas, seja para relocação de famílias de agricultores ou de estabelecimento de prognósticos, é extremamente facilitada por um bom conhecimento do comportamento morfodinâmico e do contexto fisiográfico $(6,10)$.

O auxílio à geotecnia em projetos de UHE's, abrange às avaliações dos riscos de instabilidade nas áreas marginais às represas e nas ombreiras das barragens, bem como das condições de estanqueidade dessas obras. Para isso, é de fundamental importância a utilização de modelos adequados de evolução geomorfológica em ambientes intertropicais $(2,6,8,10$, 11).

No caso da UHE de Sapucaia (2), ficou claro que os movimentos de massa, tanto estabilizados como ainda ativos, expressam a dinâmica geomorfológica em condições naturais, devendo ser reativados e/ou acelerados pelo levantamento do NA, gerando riscos de grandes proporções, sem que projetos de reflorestamento possam configurar soluções indubitáveis. No caso da UHE de Guilman-Amorim (11), uma quase tragédia com importante custo financeiro para a empresa construtora, poderia ter sido evitada se os geomorfólogos que atuaram no EIA/RIMA tivessem interpretado os relevos de pontões à luz, não só dos processos intempéricos que geram feições esferoidal, mas também dos efeitos do alívio de tensões em maciços anteriormente confinados, quando da escavação dos vales. Deste modo, teriam previsto certas probabilidades para a existência de fraturas de alívio (acebolamento) dentro do maciço e, consequentemente, recomendado estudos geotécnicos complementares antes das escavações nas ombreiras.

Vários projetos de UHE no Brasil têm enfrentado problemas de estanqueidade das barragens. Na maior parte dos casos, as fugas d'água tinham como causa a ocorrência de modelados cársticos, o que é geralmente previsto frente à simples presença de rochas calcárias. A dificuldade aumenta sensivelmente quando as perdas d'água são controladas por estruturas geológicas ou presença em profundidade de lateritas espessas e porosas.

\section{AGEOMORFOLOGIA COMOSUPORTE ESPACIAL E CONCEITUAL PARA AS SÍNTESES GEO-AMBIENTAIS}

Ao recordar as características do sistema ambiental dentro do qual se encontra inserida a dinâmica geomorfológica, pode-se demonstrar que a compartimentação geomorfológica, realizada com base nos atributos fisiográficos e edáficos e geodinâmicos, constitui uma base espacial altamente adequada ao estabelecimento das sínteses geo-ambientais, hoje solicitadas até pelas equipes de engenheiros encarregados dos projetos executivos $(1,4,5)$.

Esta prática foi utilizada, repetidamente e com sucesso, nos caso das áreas de influência das UHE's de Igarapava, Caraíbas e Porto Estrela, considerando como unidades geo-ambientais fundamentais os "compartimentos geo-morfo-pedológicos". Estes não expressam, evidentemente, apenas correspondências 
espaciais entre geologia, geomorfologia e pedologia, mas modelos de inter-relações válidos para cada caso específico. A nível de mapeamento, também, demonstrou-se a importância do uso de técnicas de representação que ressaltem a terceira dimensão, ou seja que permitem visualizar os volumes morfológicos como suporte das paisagens globais $(4,6 / 7)$.

$\mathrm{Na}$ sequência da conceituação adotada para a geomorfologia em áreas inter-tropicais, é lícito considerar a evolução morfogenética passada e a dinâmica atual, como bases fundamentais do prognóstico sobre a dinâmica ambiental pósrepresamento. Isto porquê, neste caso, os fluxos de matéria sólida ligados aos processos de erosão, confundem-se muito com os fluxos geoquímicos que interligam todos os processos ocorrendo na biosfera. Por extensão, ao objetivar uma ocupação racional do espaço, a dinâmica sócio-econômica não pode ignorar a estruturação tridimensional das paisagens. Esta concepção foi aplicada no caso da área de influência de Igarapava $(1,4)$, para a qual foi elaborado um "Mapa do Prognóstico Ambiental", sintetizando os principais impactos ambientais do emprendimento sobre o meio e inversamente. O mapa foi concebido para ser autosuficiente: toda a informação, incluindo as dimensões espacial e temporal, os circuitos de geração e transmissão de impactos, as retro-ações, bem como os aspectos quantitativos, são adquiridos de maneira sintética pela simples observação do mapa junto com uma legenda central sob forma de tabela de fluxos.

\section{AS CONTRIBUIÇÕESDA GEOMORFOLOGIA À TOMADA DE DECISÕES TÉCNICASE OPERACIONAIS}

Os estudos geomorfológicos para projetos de UHE's assumem importância fundamental no conjunto dos EIA's/RIMA's ou RCA's/PCA's, na medida em que não forem concebidos apenas como estudos descritivos de feições fisiográficas e de formas de erosão. Esses estudos têm de objetivar a análise da dinâmica do relevo, em suas inter-ações permanentes com a dinâmica da biosfera como um todo. Devem também ser formatados em função de finalidades definidas pelas características específicas aos projetos de barramento de rios e seus aspectos operacionais: geração de represa retentora de sedimentos, inundação de fundos de vales com seus recursos naturais, levantamento do nível d'água nas encostas, restituição de água menos turva a jusante da barragem, transformação de uma corrente fluvial numa massa d'água lacustre às vezes com espessura de 100 metros ou mais, entre outros.

Isto mostra que esses estudos podem e devem auxiliar os tomadores de decisões em assuntos que ultrapassam os problemas ligados à dinâmica do meio físico.

Um dos problemas fundamentais e permanentes deve ser o da avaliação dos riscos de assoreamento da futura represa, através da delimitação, localização e caracterização das áreas-fontes de sedimentos em situações instáveis. Devem ser caracterizados seus volumes, condições e vias de trânsito e deposição das cargas sólidas resultando de sua erosão. No entanto, no Brasil, a falta de dados pertinentes de sedimentometria dificulta a realização desta tarefa por inteiro. Porém, isto não elimina a obrigação de, pelo menos, delimitar as áreas-fontes de carga sólida e determinar suas condições de erodibilidade, para facilitar a priorização dos investimentos no monitoramento dos processos de erosão na bacia contibuinte $(8,12)$.

O segundo problema muito recorrente é o da avaliação dos riscos de instabilidade das encostas marginais à represa, uma vez que o represamento eleva o nível piezométrico submetendo os materiais superficiais a novas condições hídricas. Trata-se, portanto de prognosticar a situação de estabilidade geotécnica a ser gerada, baseando-se no comportamento morfodinâmico atual e nas alterações que serão introduzidas nas encostas. Em função disso, deve-se elaborar um plano de controle e monitoramento das condições de estabilidade das margens da represa $(2,6,8,10,11)$. No caso da UHE de Porto Estrela (10), este plano incluiu a contratação de um geomorfólogo para visitas e levantamentos periódicos, pois o maior potencial de deslizamentos reside na presença de pacotes aluviais arenosos com espessuras de até 80 metros.

Um problema de abordagem mais difícil, é o da avaliação dos efeitos erosivos das águas com menor turbidez, restituídas a jusante da barragem. O alívio de parte da carga sólida traduz-se, geralmente, por um sensível acréscimo de agressividade erosiva, sobretudo para com os leitos fluviais e suas margens, quando modelados em rochas brandas. No entanto, uma avaliação qualitativa razoável é possível, quando se dispõe de dados precisos de projeto e que o trecho fluvial de interesse apresenta uma dinâmica equilibrada. O caso onde este tipo de prognóstico é mais fácil de elaborar, é certamente o das planícies de meândros (10).

Os estudos geomorfológicos, ao ater-se também às coberturas superficiais, desmbocam obrigatoriamente na identificação de recursos minerais. Estes podem ter origem supergênica, relacionada com processos de intensa lixiviação associada ao soerguimento de áreas aplainadas e latossolizadas. É o caso muito frequente, nestas latitudes, de jazidas de ferro, manganês, bauxita, entre outros (8). Por outro lado, a identificação dos testemunhos das paleoredes fluviais abre caminho para a localização de placeres nas regiões com potencial aurífero e/ diamantífero (8). Isto traz informações fundamentais para os prognósticos ambientais, pois permite projeções para o desenvolvimento das atividades minerárias.

Com o avanço dos conhecimentos sobre a neotectônica da Plataforma Brasiliana e seus métodos de estudo, os trabalhos geomorfológicos devem decortinar melhor este aspecto, contribuindo de maneira fundamental à avaliação do risco sísmico, induzido ou 
não $(2,8,9,11)$.

Por fim, a análise da relação das feições geomorfológicas com as características globais do projeto pode revelar possibilidades de contribuição inesperadas. É o caso da UHE de Irapé, em que os patamares de terraços mais elevados, foram identificados como as unidades morfo-pedológicas mais adequadas para a relocação das famílias, que deverão ser desalojadas dos "grotões" onde sobreviviam miseravelmente (12). Nesses terraços deveriam encontrar águas limpas próximas, solos razoavelmente agricultáveis e melhor acesso as servicós de atendimento social (8).

\section{REFERÊNCIASBIBLIOGRÁFICAS}

1 - CAMPOS, J.F.C.; SAADI, A. MARINHO, M.B.S. \& CARMO, V.A. do 1992. Mapeamento do prognóstico ambiental da UHE de Igarapava-MG. Anais $2^{\circ}$ Simp. Situaç. Amb. e Qual. de Vida na RMBH e MG., ABGE/ MG, Belo Horizonte-MG, 1992, pp.104-106.

2 - SAADI, A. \& VALADÃO, R.C. 1988. UHE Sapucaia: Estudo morfodinâmico das encostas do Circuito Hidráulico do Aproveitamento de Sapucaia. Rio de Janeiro, Centrais Energéticas Furnas/Leme Engenharia S.A. ( 40 p. + mapas).

3 - SAADI, A. 1989. Avaliação de impactos no Brasil: problemas e perspectivas. Anais do $3^{\circ}$ Simp. de Geog. Fís. Aplic., IG/UFRJ, Nova Friburgo-RJ, 1989, pp. 1428.

4 - SAADI, A. (Coord.) 1989. Mapeamento do Diagnóstico e Prognóstico Ambientais da Área de Influência da UHE de Igarapava, MG-SP. Belo Horizonte, CEMIG/IEESA/ TERRA Consult. (30 p.+ 2 mapas 1/50.000:1P/B e 1 a cores)

5 - SAADI, A. (Coord.) 1989. Recomendações e orientações metodológicas para o levantamento de dados básicos, visando a elaboração de mapeamentos sintéticos em estudos de EIA/RIMA de UHE's. Belo Horizonte, CEMIG/ TERRA Consult.

6 - SAADI, A. (Superv.) 1990. Plano de Controle AmbientalPCA: Aproveitamento hídrico da bacia do ribeirão Caraíbas, bacia do rio Salinas, Minas Gerais. Belo Horizonte, CEMIG/TERRA Consult. (200 p. + mapas)

7 - SAADI, A. (Superv.) 1990. Relatório de Controle AmbientalRCA: Aproveitamento hídrico da bacia do ribeirão Caraíbas, Bacia do rio Salinas, MInas Gerais. Belo Horizonte, CEMIG/TERRA Consult. (150 p. + mapas)

8 - SAADI, A.; MAGALHÃES Jr. \& MARQUES, M.R. 1991. Estudos Básicos da Fase de Viabilidade da UHE de IRAPÉMG: Relatório de Geomorfologia da Área de Influência. Belo Horizonte, CEMIG/ENERCONSULT Ltda. (70 p. + mapas)

9 - SAADI, A. 1992. Relatório para argüição das conclusões do Relatório de Geomorfologia da Área de Influência da UHE de IRAPÉ-MG. Belo Horizonte, CEMIG/ENERCONSULT Ltda. (15 p.)

10 - SAADI, A. (Coord.) 1994. EIA/RIMA do Aproveitamento Hidrelétrico do Rio Santo Antônio em Cachoeira de Porto Estrela. Relatório do Meio Físico. Belo Horizonte, MENDES JÚNIOR S.A./TERRA Consult. (160 p. + mapas)

11 - SAADI, A. 1995. Estabilidade das encostas da Área de Influência da UHE de Guilman-Amorim, Nova Era-MG. Belo Horizonte, ANDRADE GUTTIEREZ/DAM Eng. (25p. + mapa)

12 - SAADI, A. 1997. A geomorfologia do Planalto do Espinhaço Setentrional avaliada para a implantação de barragem: a UHE de Irapé-MG. (neste simpósio) 